McLean, S. J. (1953). J. gen. Microbiol. 9, 110-118.

\title{
Identification of Strains of Streptococcus pyogenes of Types 5, 11, 12, 27 and 44 by the Precipitin Test for the $T$ Antigen
}

\author{
By SIBELY J. McLEAN* \\ Streptococcal Reference Laboratory, Public Health Laboratory Service, \\ Colindale Avenue, London, N.W. 9
}

SUMMARY: Strains of Streptococcus pyogenes belonging to Types 5, 11, 12, 27 and 44 share a minor $T$ antigen. In addition, there are three major $T$ antigens in this set of types, one in Type 11, one in Type 12 and the third common to Types 5, 27 and 44.

T antigen, prepared by Pakula's method, is a satisfactory fraction for absorbing the antibodies from serum, the advantage being that very little serum is lost with each absorption because the volume of $T$ antigen required is so small. The Pakula method of extraction of the $T$ antigen can also be satisfactorily used in routine typing. Type 11 strains can be definitely identified by the $T$ precipitin test, and this test can also be used for identifying Type 12 strains that give no reaction with Type 12 anti-M sera. There are some strains which have agglutination patterns of the series $5,11,12,27$ and 44 but which give no precipitation with the $T$ antisera. It may be that in these the major $T$ antigen has not been recognized.

Streptococci of Lancefield's Group A (Streptococcus pyogenes) generally have two type-specific antigens, known as $M$ and $T$. Lancefield (1940-1) proposed that the $M$ antigen should be regarded as determining the type of a strain because no strain was known to carry more than one $M$ antigen, and also because the $M$ antigen was more closely related to virulence than the $T$ antigen. Moreover, the $\mathbf{M}$ antigen could be recognized by the readily standardized micro-precipitin test (Swift, Wilson \& Lancefield, 1943). However, it has been a common experience that it is practically impossible to make anti-M precipitating sera for streptococci of a number of the types that Griffith (1934) recognized by slide-agglutination tests, even with strains freshly isolated from patients; strains of such types still have to be recognized by the agglutination method.

Slide-agglutination typing is well known to be complicated by mutual crossreactions with certain series of types. In two such series-those comprising Types 15, 17, 19, 23 and 30, and Types 4, 24, 26, 28, 29 and 46-the cause of the cross-reactions has been shown to be a sharing of one or more $T$ antigens (Stewart, Lancefield, Wilson \& Swift, 1944). However, the type of these strains can be often decided by the $\mathbf{M}$ precipitin test since satisfactory anti-M sera for all types, except perhaps Type 4, are available.

Griffith (1934) recognized a cross-reaction between his Types 11 and 12, and in our experience the series of Types 5, 11, 12, 27 and 44 commonly show varying degrees of cross-reaction. With this series, the type of a strain cannot

\footnotetext{
* Present address: Department of Bacteriology, University of Adelaide, South Australia.
} 
always be determined by the $M$ antigen because we have been unable to prepare satisfactory anti-M sera for Types 11,27 or 44 .

The present paper reports an investigation of the $\mathrm{T}$ antigens responsible for the cross-reactions among Types 5, 11, 12, 27 and 44, in which use has been made of the method devised by Pakula (1951) for the extraction of the $T$ antigen. This investigation led to a means for the recognition of Type 11 strains in routine work by the $\mathrm{T}$-precipitin test.

\section{MATERIALS AND METHODS}

Strains. The strains used in the preliminary investigations were:
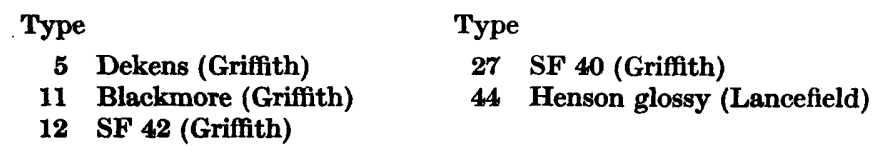

For the subsequent investigation of a routine typing method, strains obtained from three sources were used:

(1) Strains sent to this laboratory for type identification.

(2) Strains isolated here during a large scale epidemiological survey of streptococcal infection in children.

(3) A collection of strains sent from the United States as untypable by the M precipitin test.

The strains were selected because they were agglutinated by some or all of the sera for the five types, $5,11,12,27$ and 44, and gave no reaction with the available $M$ sera, namely those for Types 5 and 12 .

Preparation of antisera. Antisera were prepared by repeated intravenous inoculation of rabbits with vaccines that had been grown at $22^{\circ}$ to increase the production of $\mathbf{T}$ antigen, digested with pancreatic extract (Cole \& Onslow), and killed with formalin. The pancreatic digestion destroyed the $\mathbf{M}$ antigen so that anti-T sera were produced. Group antibodies were removed from the serum by absorption with a suspension of Type 6 'glossy' organisms.

\section{Extraction of the $T$ antigen}

Preparation of $T$ fraction for use in absorptions. The $T$ antigen was extracted by a slight modification of Pakula's method. Cultures were grown in 21 . amounts of nutrient broth $+0.5 \%$ glucose for 2 days. Incubation was at $22^{\circ}$ to enhance the production of $T$ antigen. The cultures were heated to $80^{\circ}$ for $10 \mathrm{~min}$. and then allowed to settle overnight, when the clear supernatant could be siphoned off. The deposit was washed twice with saline and suspended in $21.6 \mathrm{ml}$. phosphate buffer, $\mathrm{pH} 7 \cdot 8 ; 2.4 \mathrm{ml}$. pancreatic extract were added, the $\mathrm{pH}$ value was brought to 8.2 and the mixture digested at $50^{\circ}$ for $2 \mathrm{hr}$. The supernatant was acidified to $\mathrm{pH} 2.5$ to precipitate the $\mathrm{T}$-containing fraction and left overnight in the cold. The centrifuged deposit from this contained the $T$ antigen in a concentrated form and was the fraction used for the absorptions.

Preparation of $\mathbf{T}$ extracts for use in $T$ precipitin tests. Pakula prepared his $\mathbf{T}$ extracts from at least $250 \mathrm{ml}$. of culture, and in some cases found $500 \mathrm{ml}$. or 11 . 
necessary. Preliminary tests showed, however, that $100 \mathrm{ml}$. amounts of culture gave satisfactory results if the culture grew well and if the extracted $T$ antigen was precipitated by acid and redissolved in a small quantity of buffer. The method of extraction was that given above, using $2.7 \mathrm{ml}$. phosphate buffer and $0.3 \mathrm{ml}$. pancreatic extract. After acid precipitation the deposit was dissolved in $0 \cdot 1 \mathrm{ml}$. phosphate buffer $\mathrm{pH} \mathbf{7 \cdot 8}$. This constituted the $\mathrm{T}$ extract, which was used for precipitin tests in capillary tubes (Swift et al. 1943).

\section{Absorption of antisera with $T$ antigen}

Preliminary absorptions, using Type 12 serum undiluted and diluted 1/2.5 and $1 / 5$ with saline, showed that the serum diluted $1 / 5$ still gave a reasonable precipitate with the homologous $T$ extract and was much more readily absorbed than the undiluted serum. Accordingly, all the absorptions were done with serum diluted 1/5. Phosphate buffer, $\mathrm{pH} 7 \cdot 8$, was used as diluting agent instead of saline because otherwise repeated absorption with $\mathbf{T}$ concentrate at $\mathrm{pH} \mathrm{2.5}$ lowered the $\mathrm{pH}$ of the serum and interfered with subsequent testing by precipitation.

Absorptions were carried out using the $T$ precipitate from $250 \mathrm{ml}$. of culture to $0.5 \mathrm{ml}$. of diluted serum. The mixture was incubated at $37^{\circ}$ for $2 \mathrm{hr}$. and left overnight in the cold if necessary. After each absorption the serum, together with an unabsorbed control, was tested by two methods: slide agglutination with suspensions of all five types $(5,11,12,27,44)$ and precipitation with $\mathrm{T}$ extracts of each type. Absorption was continued until all the antibodies for the homologous extract were removed. The number of absorptions required varied from one to three with different sera.

Agglutination tests. These were done by the slide method using suspensions grown in buffered broth containing $0.2 \%$ glucose for 2 days at $22^{\circ}$. If any of the suspensions were granular they were treated with pancreatic extract at $50^{\circ}$ for $20 \mathrm{~min}$. The suspensions used for titrating the five types of sera and for testing the absorbed sera were similarly treated to destroy the $\mathbf{M}$ antigens.

\section{RESULTS}

Related $T$ antigens in types $5,11,12,27$ and 44

\section{Demonstration of the cross-reactions between the five types}

Slide-agglutination and T-precipitin tests suggested that the five types have a $T$ antigenic component in common, and that, in addition, Types 5,27 and 44 share a major $\mathrm{T}$ antigen (Table 1 ).

Pakula (1951) showed the presence of related $T$ antigens in Types 12, 27 and 44; Types 27 and 44 shared a major $T$ antigen as shown by degree of crossagglutination and by the fact that their $\mathbf{T}$ extracts precipitated well with sera of both types. Type 12 had a major $T$ antigen of its own, as it only agglutinated to low titres with sera of Types 27 and 44 and its $T$ extract did not precipitate with these sera. The relationship is confirmed by the results in Table 1, which also indicate that Type 11, like Type 12, has a major $T$ antigen of its own, whereas Type 5 shares the $T$ antigen of Types 27 and 44 . 


\section{The relationship of the $T$ antigens as shown by reciprocal absorptions}

Preliminary work with Type 12 serum showed that absorption of the $\mathbf{T}$ antibody with a suspension of Type 12 organism sometimes required as many as five or six absorptions, and this led to the loss of an appreciable amount of serum. The use of a concentrated T antigen extracted by Pakula's method proved more effective in absorption and led to little loss of serum.

Table 1. Agglutination- and $T$-precipitin reactions showing that Types 5, 11, 12, 27 and 44 have related $T$ antigens

\begin{tabular}{|c|c|c|c|c|c|c|c|c|c|c|c|}
\hline \multirow[b]{3}{*}{ Antisera } & \multirow{3}{*}{$\begin{array}{c}\text { Temperature } \\
\text { of incubation } \\
\text { for growth } \\
\text { of culture } \\
\left({ }^{\circ}\right)\end{array}$} & \multicolumn{10}{|c|}{ Reactions in agglutination and precipitin tests with strains of Types } \\
\hline & & \multicolumn{2}{|r|}{5} & \multicolumn{2}{|c|}{11} & \multicolumn{2}{|c|}{12} & \multicolumn{2}{|r|}{27} & \multicolumn{2}{|r|}{44} \\
\hline & & Agg. & Ppt. & Agg. & Ppt. & Ágg. & Ppt. & Agg. & Ppt. & Agg. & Ppt. \\
\hline Type 5 & $\begin{array}{l}\mathbf{2 2} \\
\mathbf{3 7}\end{array}$ & $\begin{array}{r}160 \\
1\end{array}$ & $\begin{array}{c}++ \\
.\end{array}$ & $\begin{array}{r}5 \\
10\end{array}$ & - & -5 & - & $\begin{array}{l}320 \\
160\end{array}$ & $\begin{array}{c}+++ \\
.\end{array}$ & $\begin{array}{l}320 \\
320\end{array}$ & $\begin{array}{c}+++ \\
.\end{array}$ \\
\hline Type 11 & $\begin{array}{l}\mathbf{2 2} \\
\mathbf{3 7}\end{array}$ & - & - & $\begin{array}{l}160 \\
160\end{array}$ & $\begin{array}{c}++ \\
.\end{array}$ & - & - & $\begin{array}{l}1 \\
1\end{array}$ & - & - & - \\
\hline Type 12 & $\begin{array}{l}\mathbf{2 2} \\
\mathbf{3 7}\end{array}$ & 1 & - & $\begin{array}{l}1 \\
1\end{array}$ & - & $\begin{array}{l}160 \\
160\end{array}$ & ++ & $\begin{array}{r}5 \\
20\end{array}$ & - & - & - \\
\hline Type 27 & $\begin{array}{l}22 \\
37\end{array}$ & $\begin{array}{c}320 \\
-\end{array}$ & $\begin{array}{c}++ \\
.\end{array}$ & $\begin{array}{l}5 \\
5\end{array}$ & $\overline{-}$ & $\begin{array}{l}1 \\
1\end{array}$ & - & $\begin{array}{l}\mathbf{3 2 0} \\
\mathbf{3 2 0}\end{array}$ & $\begin{array}{c}++t \\
.\end{array}$ & $\begin{array}{l}320 \\
320\end{array}$ & $\begin{array}{c}t+t \\
.\end{array}$ \\
\hline Type 44 & $\begin{array}{l}22 \\
37\end{array}$ & $\begin{array}{c}160 \\
-\end{array}$ & $\begin{array}{c}++ \\
.\end{array}$ & - & - & - & - & $\begin{array}{l}\mathbf{3 2 0} \\
\mathbf{3 2 0}\end{array}$ & $\begin{array}{c}+++ \\
.\end{array}$ & $\begin{array}{l}160 \\
160\end{array}$ & $\begin{array}{c}+++ \\
.\end{array}$ \\
\hline
\end{tabular}

The figures are the reciprocal of the highest dilution at which agglutination (Agg.) still occurred; $-=$ no agglutination. Decreasing strength of precipitation (Ppt.) indicated by the symbols ++++ , ,,,$++++++ \pm ;-=$ no precipitation. Precipitation results read after incubation at $37^{\circ}$ for 2 hr. and refrigeration overnight.

Antisera for each of the five types were first absorbed with Type 6 'glossy' organisms to remove group antibodies. Portions of each serum were then absorbed with $\mathrm{T}$ antigen from each type until all the antibodies for the type used for absorption had been removed. Absorbed sera were tested both by slide agglutination and $T$ precipitation with suspensions or extracts of all five types (Table 2). The strength of the precipitin reactions in this table is generally less than in Table 1 as the sera used in these experiments were diluted 1/5.

Type 11 has a distinct $T$ antigen and its agglutinins and precipitins were not removed from the antiserum by absorption with the other four types although they were decreased, possibly because the serum required three absorptions. Type 11 also only absorbed the agglutinins for itself from the sera for Types 5, 27 and 44. In the same way Type 12 has a distinct $T$ antigen. Types 5,27 and 44 each removed the agglutinins and precipitins from the sera for Types 5 , 27 and 44, although Type 5 did not remove all the agglutinins from the sera of Types 27 and 44, probably because the absorbing extracts were not as strong as those of 27 and 44.

It appears, therefore, that there are three major $T$ antigens in this set of five strains, one in the Type 11 strain, another in the Type 12 and a third in the strains of Types 5, 27 and 44. Type 5 produces little or none of this antigen 
when grown at $37^{\circ}$, and when grown at $22^{\circ}$ usually produces less than Types 27 and 44 as shown by the amount extracted by Pakula's method.

Table 2. Reciprocal absorptions showing relationship of $T$ antigens of Types 5, 11, 12, 27 and 44

Reactions in agglutination and precipitin tests with strains of Types

Antisera diluted 1:5

Type 5 serum

Unabsorbed

Absorbed with Type 5

Absorbed with Type 11

Absorbed with Type 12

Absorbed with Type 27

Absorbed with Type 44

Type 11 serum

Unabsorbed

Absorbed with Type 5

Absorbed with Type 11

Absorbed with Type 12

Absorbed with Type 27

Absorbed with Type 44

Type 12 serum

Unabsorbed

Absorbed with Type 5

Absorbed with Type 11

Absorbed with Type 12

Absorbed with Type 27

Absorbed with Type 44

Type 27 serum

Unabsorbed

Absorbed with Type 5

Absorbed with Type $11 \quad 160$

Absorbed with Type $12 \quad 160$

Absorbed with Type 27

Absorbed with Type 44

Type 44 serum

Unabsorbed

Absorbed with Type $5 \quad 10$

Absorbed with Type $11 \quad 160$

Absorbed with Type $12 \quad 160$

Absorbed with Type 27 -

Absorbed with Type 44

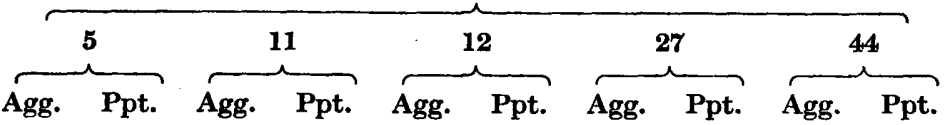

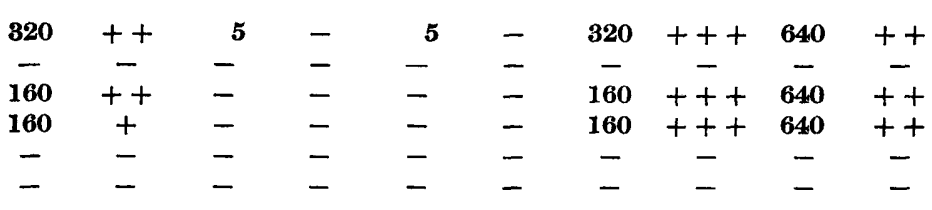

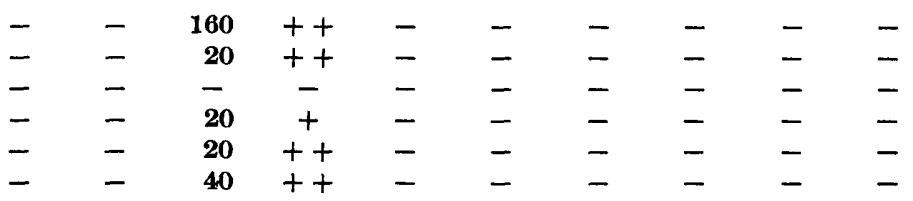

$\begin{array}{lllllllll}- & - & - & 320 & + & 5 & - & 5 & - \\ - & - & - & 160 & + & - & - & - & - \\ - & - & - & 160 & + & - & - & - & - \\ - & - & - & 160 & + & - & - & - & -\end{array}$

$60++5-5$

$\begin{array}{lcccc}++ & 5 & - & 5 & - \\ - & - & - & - & -\end{array}$

$+5=-$

$\begin{array}{rcrc}320 & +++ & 640 & ++ \\ 5 & - & 10 & - \\ 320 & ++ & 640 & ++ \\ 160 & ++ & 640 & ++ \\ - & - & - & -\end{array}$

$++5=$
$-5=$
$++=$
$++=$

$\begin{array}{rrrrrr}\mathbf{5} & - & \mathbf{3 2 0} & +++ & \mathbf{3 2 0} & ++ \\ - & - & \mathbf{2 0} & - & \mathbf{2 0} & - \\ - & - & \mathbf{3 2 0} & + & \mathbf{3 2 0} & + \\ - & - & \mathbf{1 6 0} & ++ & \mathbf{3 2 0} & + \\ - & - & - & - & - & - \\ - & - & - & - & - & -\end{array}$

Conventions as in Table 1.

These results also show that the $T$ antigen fraction is satisfactory for use in serum absorption; it is largely dissolved in the diluted serum and any precipitate that forms can be readily removed by centrifugation. Very little serum is lost with each successive absorption. 


\section{Routine identification of Type 11 strains by the T-precipitation test}

For routine typing of streptococci it is desirable to have a method in which the unknown strain reacts with the serum of only one type. This is not always possible with the slide-agglutination method because of cross-reactions due to the sharing of $\mathbf{T}$ antigens by certain types. The alternative Lancefield $\mathbf{M}$ precipitation method is also impracticable for some types, such as 11, 27, and 44, because of the difficulty of preparing $M$ antisera.

This paper has shown that it is possible to distinguish Type 11 from Types 5, 12,27 and 44 by the T-precipitin test, precipitation being obtained only with the homologous serum. Pakula found that $\mathrm{T}$ extracts gave precipitation with sera with agglutinating titres of $1 / 160$ or more. Type 11 strains agglutinate with sera of Types 5, 12, 27 and 44 to low titre so that the result from agglutination tests with sera at low dilution is a 'pattern', but these heterologous reactions are eliminated by the T-precipitin test. Further investigation was therefore carried out to test whether $T$ precipitation was of value in routine typing, with special reference to the identification of Type 11 strains.

As a preliminary trial all our stock strains of Types 5, 11, 12, 27 and 44, were tested by agglutination and $T$ precipitation (Table 3). Type 5, 27 and 44 organisms had agglutination patterns with strong reactions with the sera for Types 5, 27 and 44, as would be suspected from the results of the previous work. Type 11 organisms agglutinated strongly with Type 11 serum and also agglutinated with Type 27 and 44 sera, while Type 12 organisms agglutinated with Type 12, 27 and 44 sera. The T-precipitin tests agreed well with the agglutinations.

The method of extraction having proved satisfactory with these stock strains, seventy-six new strains were then tested in a similar manner (Table 4). The 'original agglutination patterns' were those given when the strain was first received in the laboratory and the 'repeat agglutination patterns' were those given when the' strains were re-tested, sometimes several months later. The agglutination patterns, and the strength of the individual reactions in each pattern, remained fairly constant with strains that gave a positive T-precipitin reaction, but were more variable with the strains that failed to precipitate with any of the five sera. Using the results of Table 3, the type of each new strain could be inferred from the strength of the reactions in its agglutination pattern.

There were twenty-six strains having agglutination patterns which did not fit into any of those in Table 3, and none of these strains gave any reaction in the T-precipitin test. When strains gave a negative reaction, the extraction and precipitation were repeated, and if the results were still negative the extraction was repeated again from $250 \mathrm{ml}$. of culture, before being finally regarded as negative.

There are two possible explanations of the failure of these strains to precipitate with the T sera. Since they have agglutination patterns there must presumably be some $\mathbf{T}$ antigens present. Therefore, either the method of extraction is not suitable, which seems unlikely in view of the number of 
strains that do give positive results, or these agglutinations with Types 5,11 , 12,27 and 44 are minor reactions, and the major $T$ antigens of these strains are not yet identified. If this were so, these strains should only agglutinate to low titres with the five antisera. Several of these negative strains and several strains giving positive results in the $T$-precipitin test were titrated against the

\section{Table 3. Agglutination patterns and T-precipitation results of stock strains}

\begin{tabular}{|c|c|c|c|c|c|c|c|c|}
\hline & & & & & T precip & itation. A & Antisera & \\
\hline Strain & Source & Agglutin & nation pattern & Type 5 & Type 11 & Type 12 & Type 27 & Type 44 \\
\hline Type 5 & & & & & & & & \\
\hline Dekens & Griffith & $5^{++} 27^{++}$ & $44^{++}$ & + & - & - & + & + \\
\hline Veen & Griffith & $5^{++} 27^{++}$ & $44^{++}$ & ++ & - & - & ++ & ++ \\
\hline T5 B & Lancefield & $5^{++} \mathbf{2 7}++$ & $44^{++}$ & ++ & - & - & ++ & + \\
\hline R51.479 & Routine & $5^{++} 27^{++}$ & $44^{++}$ & + & - & - & ++ & + \\
\hline R51.776 & Routine & $5^{++} \mathbf{2 7} 7^{++}$ & $\mathbf{4 4} \mathbf{4}^{++}$ & + & - & - & + & + \\
\hline B8100 & Routine & $5^{++} 12^{ \pm}$ & $27^{++} 44^{++}$ & + & - & - & ++ & \pm \\
\hline Type 11 & & & & & & & & \\
\hline Adams & Griffith & $11^{++} 12^{+}$ & $\mathbf{4 4}^{++}$ & - & +++ & - & - & - \\
\hline Bethell & Griffith & $11^{++} 27^{++}$ & $44^{++}$ & - & ++ & - & - & - \\
\hline Blackmore & Griffith & $11^{++} 44^{++}$ & & - & ++ & - & - & - \\
\hline Curtis & Griffith & $11++27^{++}$ & $\mathbf{4 4}++$ & - & ++ & - & - & - \\
\hline Dobson & Griffith & $11^{++} 27^{+}$ & $\mathbf{4 4}^{++}$ & - & +++ & - & - & - \\
\hline T11 & Lancefield & $11^{++} 27^{+}$ & $\mathbf{4 4}^{++}$ & - & ++ & - & - & - \\
\hline Type 12 & & & & & & & & \\
\hline SF 42 & Griffith & $12^{++} 27^{ \pm}$ & $\mathbf{4 4}^{++}$ & - & - & ++ & - & - \\
\hline 869 & Routine & $12^{++} 27^{+}$ & $\mathbf{4 4}++$ & - & - & ++ & - & - \\
\hline R47.3722/17 P.S. & Routine & $12^{++} 44^{+}$ & & - & - & ++ & - & - \\
\hline R.1518 & Routine & $12^{++} 44^{++}$ & & - & - & ++ & - & - \\
\hline R 50.41 & Routine & $12^{++} 44^{+}$ & & - & - & ++ & - & - \\
\hline R51.178 & Routine & $12^{++} 44^{+}$ & & - & - & ++ & - & - \\
\hline В 8400 & Routine & $12^{++} 44^{++}$ & & - & - & ++ & - & - \\
\hline Type 27 & & & & & & & & \\
\hline Makinson & Griffith & $5^{++} 11^{+}$ & $12+27^{++} 44^{++}$ & ++++ & - & - & +++ & +++ \\
\hline Prince Smith & Griffith & $5^{++} 11^{+}$ & $27^{++} 44^{++}$ & + & - & - & + & + \\
\hline Q49 T & Griffith & $5^{++} 11^{+}$ & $12^{+} 27^{++} 44^{++}$ & +++ & - & - & +++ & +++ \\
\hline ERY & Griffith & $5^{++} 11^{ \pm}$ & $12^{ \pm} 27^{++} 44^{++}$ & ++ & - & - & ++ & ++ \\
\hline SF 40 & Griffith & $\mathbf{5}^{++} \mathbf{2 7} \mathbf{7}^{++}$ & $44^{++}$ & ++ & - & - & ++ & ++ \\
\hline $\mathrm{T} 27 / 46$ & Lancefield & $5^{++} 11+$ & $12^{+} 27^{++} 44^{++}$ & +++ & - & - & +++ & +++ \\
\hline T27 A/32 & Lancefield & $5^{++} 11^{ \pm}$ & $12^{+} \quad 27^{++} 44^{++}$ & +++ & - & - & +++ & +++ \\
\hline Type 44 & & & & & & & & \\
\hline A402EG18 & Griffith & $\mathbf{5}^{++} \mathbf{2 7}^{++}$ & $\mathbf{4 4}++$ & ++ & - & - & ++ & ++ \\
\hline Henson & Lancefield & $5^{++} 12^{ \pm}$ & $27^{++} 44^{++}$ & + & - & - & + & + \\
\hline
\end{tabular}

Conventions as in Table 1.

five sera (Table 5). The strains giving positive results by $\mathbf{T}$ precipitation agglutinated to high titres with the type serum with which they precipitated, but the strains giving no results by $T$ precipitation did not agglutinate to high titre with any of the five types. The agglutination patterns of these strains are therefore probably due to minor $T$ antigens and the major $T$ antigens are not yet identified. Indeed these strains could be new types. The presence of such strains, which share minor $T$ antigens with the Types $5,11,12,27$ and 44, 
confirms the usefulness of the T-precipitin test for the positive identification of these five types.

Of the seventy-six new strains that gave no reactions with Type 5 or Type 12 anti-M sera, fifty reacted in the T-precipitin test. Of these fifty strains, twentysix reacted with the Type 11 serum, twelve with Type 12, and the remaining

Table 4. Summary of agglutination patterns and T-precipitation results of new strains

$\mathbf{T}$ precipitation

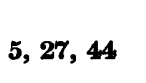

11

12

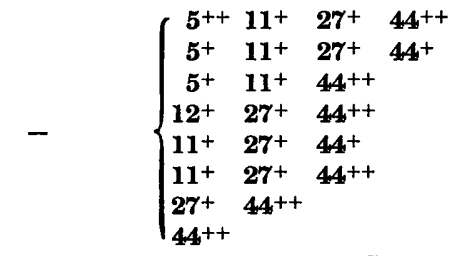

Conventions as in Table 1.
No. of strains

Repeat agglutination pattern

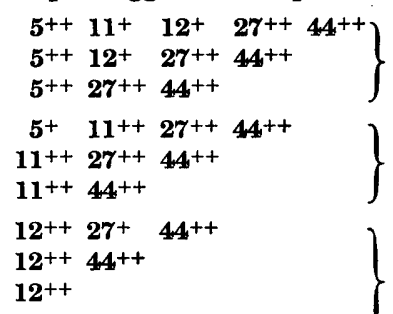

12

26

12

$5^{++} 11^{+} 27^{+} 44^{++}$

$5^{+} 11^{+} 27^{++} 44^{++}$

$5^{+} 11^{+} 44^{++}$

\begin{tabular}{|c|c|c|c|c|c|c|}
\hline \multirow[b]{2}{*}{ Strain } & \multirow{2}{*}{$\begin{array}{c}\text { Type by } \mathbf{T} \\
\text { precipitation }\end{array}$} & \multicolumn{5}{|c|}{ Agglutination titre with sera of types } \\
\hline & & $\mathbf{5}$ & 11 & 12 & 27 & 44 \\
\hline Rz 15 & $5,27,44$ & 640 & • & 5 & 320 & $\mathbf{3 2 0}$ \\
\hline 22 & 11 & 20 & 160 & 1 & 1 & 10 \\
\hline 31 & 12 & 20 & . & 640 & 5 & 80 \\
\hline 40 & $5,27,44$ & 1280 & • & $\mathbf{1}$ & 320 & 320 \\
\hline $\mathbf{5 8}$ & 11 & 10 & 80 & . & 10 & 10 \\
\hline 18 & . & 5 & . & $\mathbf{1}$ & 1 & 10 \\
\hline 23 & . & 20 & . & $\mathbf{5}$ & 10 & 20 \\
\hline 25 & . & 40 & 10 & $\mathbf{5}$ & 10 & 10 \\
\hline 46 & . & 10 & . & 5 & 1 & 10 \\
\hline 47 & . & 20 & . & 1 & 5 & 10 \\
\hline
\end{tabular}

$11+12+44++$

$11^{+} 44^{++}$

$11+44^{+}$

$44^{+}$

Table 5. Agglutination titres of groups of strains giving positive and negative results by $\boldsymbol{T}$ precipitation

twelve with the sera for Types 5, 27 and 44. As a method of identifying Type 11 strains the T-precipitin test seems very satisfactory. The type 12 strains gave no $M$ precipitation and apart from the $T$-precipitin test could not have been definitely identified.

Since the T-precipitin test only serves to eliminate the minor cross-reactions, the same result should be obtained by slide-agglutination tests using sera 
suitably diluted to remove the cross-reactions. All the new strains were retested by slide agglutination using sera diluted 1/80. As a rule the results were the same as those from the T-precipitin tests, but with some strains weak cross-reactions still occurred. To type strains with the use of diluted serum would evidently need careful preliminary titration of the serum. The T-precipitin test, however, eliminates these minor cross-reactions in all cases and so seems the method of choice.

\section{DISCUSSION}

Lancefield defined the type of Group A streptococci by the M-antigens because these were not shared by different types and could readily be detected in acid extracts by the capillary precipitin technique. It is now generally conceded that this is the method of choice for type identification of streptococci. However the M-precipitin test requires satisfactory anti-M sera, and it has been our experience that sera for some types may react with the vaccine strain but with none of a number of other strains that are judged by slide agglutination to belong to the same type. For the type identification of such strains, for which there are no satisfactory anti-M sera, we have to rely on the slide-agglutination test, and this is complicated by cross-reactions between certain types due to sharing of $\mathbf{T}$ antigens.

The present work suggests that the $T$-precipitin test may be useful for the identification of strains, such as those of Types 11, 27 and 44, for which anti-M sera are not readily prepared, and which normally give a 'pattern' reaction in slide-agglutination tests owing to their sharing of $\mathrm{T}$ antigens.

For routine type identification, a preliminary slide-agglutination test, followed by the M-precipitin test for confirmation, seems desirable. Usually this is satisfactory but when no $M$ sera are available the $T$-precipitin test can be adapted for the routine identification of many strains within the series 5,11 , 12,27 and 44.

\section{REFERENCES}

Griffith, F. (1934). The serological classification of Streptococcus pyogenes. J. Hyg., Camb. 34, 542.

LANCEFIELD, R. C. (1940-1). Specific relationship of cell composition to biological activity of hemolytic streptococci. Harvey Lect. 36, 251.

Pakula, R. (1951). Extraction of the $T$ antigen of Streptococcus pyogenes. J. gen. Microbiol. 5, 640.

Stewart, W. A., Lancefield, R. C., Wilson, A. T. \& Swift, H. F. (1944). Studies on the antigenic composition of Group A hemolytic streptococci. IV. Related T but distinct $M$ antigens in Types 15, 17, 19, 23, 30 and in Types 4, 24, 26, 28, 29, 46. Identification by slide agglutination. J. exp. Med. 79, 99.

Swift, H. F., Wilson, A. T. \& Lancefiend, R. C. (1943). Typing Group A hemolytic streptococci by $M$ precipitin reactions in capillary pipettes. J. exp. Med. 78, 127. 